\title{
Trends in extreme temperature and precipitation in Muscat, Oman
}

\section{LUMINDA N. GUNAWARDHANA \& GHAZI A. AL-RAWAS}

Department of Civil and Architectural Engineering, College of Engineering, Sultan Qaboos University, Oman luminda@squ.edu.om

\begin{abstract}
Changes in frequency and intensity of weather events often result in more frequent and intensive disasters such as flash floods and persistent droughts. In Oman, changes in precipitation and temperature have already been detected, although a comprehensive analysis to determine long-term trends is yet to be conducted. We analysed daily precipitation and temperature records in Muscat, the capital city of Oman, mainly focusing on extremes. A set of climate indices, defined in the RClimDex software package, were derived from the longest available daily series (precipitation over the period 1977-2011 and temperature over the period 1986-2011). Results showed significant changes in temperature extremes associated with cooling. Annual maximum value of daily maximum temperature (TX), on average, decreased by $1^{\circ} \mathrm{C}$ $\left(0.42^{\circ} \mathrm{C} / 10\right.$ year). Similarly, the annual minimum value of daily minimum temperature (TN) decreased by $1.5^{\circ} \mathrm{C}\left(0.61^{\circ} \mathrm{C} / 10\right.$ year), which, on average, cooled at a faster rate than the maximum temperature. Consequently, the annual count of days when TX $>45^{\circ} \mathrm{C}$ (98th percentile) decreased from 8 to 3 , by 5 days. Similarly, the annual count of days when $\mathrm{TN}<15^{\circ} \mathrm{C}$ (2nd percentile) increased from 5 to 15 , by 10 days. Annual total precipitation averaged over the period 1977-2011 is $81 \mathrm{~mm}$, which shows a tendency toward wetter conditions with a $6 \mathrm{~mm} / 10$ year rate. There is also a significant tendency for stronger precipitation extremes according to many indices. The contribution from very wet days to the annual precipitation totals steadily increases with significance at $75 \%$ level. When The General Extreme Value (GEV) probability distribution is fitted to annual maximum 1-day precipitation, the return level of a 10-year return period in 1995-2011 was estimated to be $95 \mathrm{~mm}$. This return level in the recent decade is about $70 \%$ higher than the return level for the period of 1977-1994. These results indicate that the long-term wetting signal apparent in total precipitation can be attributed largely to the increases in extreme precipitation in recent decades.
\end{abstract}

Key words climate change; RClimDex; general extreme value probability distribution; skewness

\section{INTRODUCTION}

Extreme weather events are rare, but often end up causing extensive damage to the economy, the environment and human life. For example, the super cyclonic storm, hurricane Gonu in 2007, led to the worst natural disaster on record in Oman, with total rainfall reaching $610 \mathrm{~mm}$ near the coast. The cyclone caused about $\$ 4$ billion in damage (2007 USD) and 49 deaths (Rafy and Hafez 2008). Numerous scientific research shows that these extreme events that used to be rare 50 years before are becoming frequent in many parts of the world in recent decades. Alexander et al. (2006) assessed changes in daily temperature and precipitation extremes worldwide and reported widespread significant changes in temperature extremes. They found that the trends in minimum temperature are more significant, implying that many regions become less cold rather than hotter. Similarly, Kharin and Zwiers (2005) reported that cold temperature extremes warm quicker than warm extremes in mid- and high-latitudes. Groisman et al. (2005) found that in the mid-latitudes there is a notable increase in the frequency of very heavy precipitation (upper $0.3 \%$ of daily precipitation) during the past 50-100 years. Easterling et al. (2000) revealed heavy precipitation change in Siberia, South Africa and northern Japan, while mean precipitation changes are less marked. Moreover, many studies based on increasing numbers of global circulation model (GCM) and regional climate model $(\mathrm{RCM})$ projections indicate that anthropogenic climate change could cause an increase in the frequency of extreme weather events, potentially making these extreme events more common in the future (Fowler et al. 2005, Beniston et al. 2007) .

Understanding the occurrence of past extremes is very important to avoid, or at the very least to reduce future damage. Arid and semi-arid regions are primarily concerned with chronic water stress, catastrophic floods and prolonged periods of droughts. Recently, Oman has experienced an accelerated frequency of flooding, mainly flash floods (Al-Rawas and Valeo 2010). In Oman, changes in precipitation and temperature have already begun to be detected, although a comprehensive analysis to determine long-term trends has yet to be conducted. This can mainly be 
explained by the scarcity of reasonably dense meteorological networks and the lack of long, digitally available records. With efforts to develop a long-term database, Sulatan Qaboos University now possesses quality controlled records of daily temperature (maximum, minimum and mean) over the period 1986-2011 and daily precipitation over the period 1977-2011. In this study, daily precipitation and temperature data in Muscat, Oman, were analysed using a set of climate indices, defined in the RClimDex software package. The presented results are a part of an ongoing bigger project to investigate the regional-specific changes in the frequency, severity and duration of extreme weather events across Oman in the past and future.

\section{STUDY AREA}

Oman, with an area of $309500 \mathrm{~km}^{2}$, is located in the southeastern corner of the Arabian Peninsula (Fig. 1). The climate is mainly arid or semi-arid, and has $<100 \mathrm{~mm}$ in annual rainfall on average, compared to an annual global average of $1123 \mathrm{~mm}$. Muscat, the capital city of Oman, is a coastal city, which accommodated $29.5 \%$ of the total population of Oman in 2010. The average precipitation of Muscat is $81 \mathrm{~mm}$ over the period 1977-2011 and it shows a statistically weak increasing trend at an average rate of $6 \mathrm{~mm} / 10$ year (p-value $=0.6)($ Fig. 2). The rainfall pattern proved to be irregular, averaging rain on only around 7 days per year. Consequently, the number of consecutive days of no rainfall is relatively high, which was estimated to be about 225 days per year over the period 1977-2011. The daily maximum temperature in Muscat fluctuates between 17 and $49^{\circ} \mathrm{C}$, and the daily minimum temperature is between 10 and $40^{\circ} \mathrm{C}$ over the period $1986-2011$.

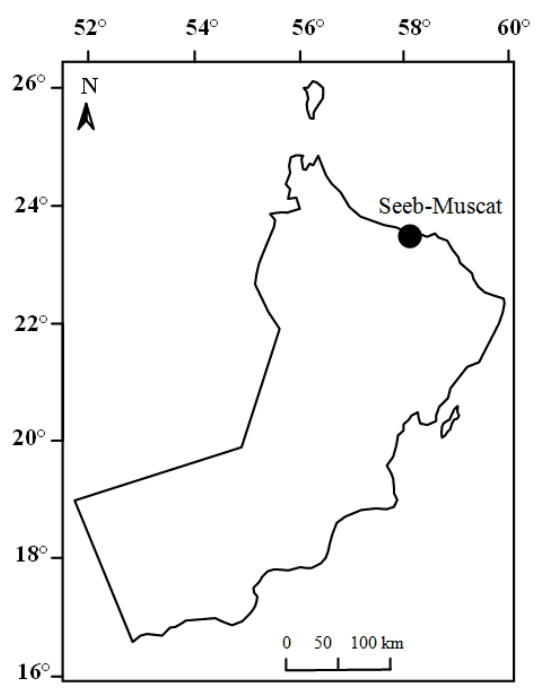

Fig. 1 Study area.

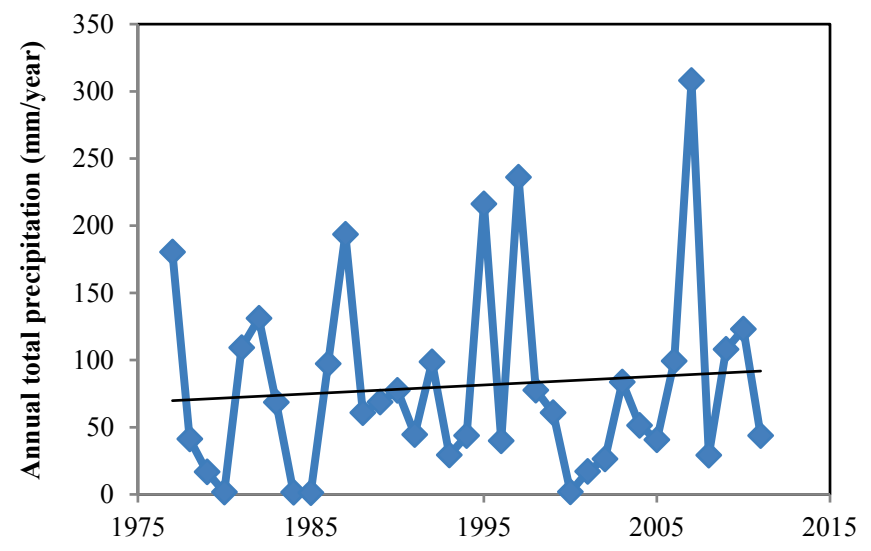

Fig. 2 Annual total precipitation in Muscat. 


\section{METHODOLOGY}

In this study, maximum and minimum temperatures, and precipitation trends were analysed using a selection of 27 indices. These indices were calculated using RClimDex software, which was developed by the Expert Team on Climate Change Detection, Monitoring and Indices (ETCCDMI) to analyse many aspects of a changing climate (Alexander et al. 2006). The quality control procedure in RClimDex was applied to identify errors in data processing. Both minimum and maximum daily temperatures were considered as missing values if daily minimum temperature is greater than daily maximum temperature. Daily maximum and minimum temperature records were defined as outliers if they lie outside the range of four standard deviations (STDEV) from the mean of the records (Mean $\pm 4 \times \mathrm{STDEV}$ ). Negative precipitation records were also considered as missing values. Homogeneity testing was conducted using a RHtest software package to identify abrupt changes in data series. However, no artificial step changes were detected.

Changes in extreme precipitation and temperatures over different periods of time were assessed by fitting the Generalized Extreme Value (GEV) distribution with three parameters: location $(\mu)$, scale $(\sigma)$ and shape $(\xi)$. These parameters were estimated by the maximum likelihood estimates method assuming a stationary climate (Jenkinson 1955). The goodness-of-fit of the fitted distribution was tested using the Kolmogorov-Smirnov test, which examines the null hypothesis that sample data follow the specified distribution. The null hypothesis was accepted at all significance levels less than calculated P-value. The cumulative probability distribution function for the GEV is:

$$
F_{(x)}=\exp \left[-\left(1+\xi \frac{x-\mu}{\sigma}\right)^{-1 / \xi}\right]
$$

Where $\{1+\xi(x-\mu) / \sigma>0\},-\infty<\mu, \xi<\infty$ and $\sigma>0$. The characteristics of extreme air temperatures and precipitation distributions were assessed in terms of return value and return periods of their annual extremes. When the annual exceedence probability is $P(X \leq x)$, the return period is calculated by the reciprocal of the $P(X \leq x)$.

$$
\text { Return period }(T)=\frac{1}{P(X \leq x)}=\frac{1}{1-P(X>x)}=\frac{1}{F_{(x)}}
$$

A $T$-year return value is defined as the threshold that is exceeded by an annual extreme in any given year with the probability $P=1 / T$ (Kharin and Zwiers 2007).

\section{RESULTS AND DISCUSSION}

The set of 27 indices used in this study includes 16 temperature-related and 11 precipitationrelated indices which describe changes in intensity, frequency and duration of temperature and precipitation events. For space reasons we are not able to present results of all indices. Instead we limit the discussion by presenting specific indices with significant impacts, together with combined indices, if the thresholds represent values of hydrological significance.

\section{Temperature indices, 1986-2011}

Figure 3(a) and (b) show trends of two percentile-based temperature indices: TN10P (percentage of days when daily minimum temperature (TN) less than 10th percentile of that during the base period) and TX10P (percentage of days when daily maximum temperature (TX) less than 10th percentile of that during the base period), which in reality represent the percentages of cold nights and cold days, respectively. Table 1 shows that positive trends apparent in the annual occurrence of cold nights and cold days are all statistically significant at the 5\% level. Similarly, the annual number of warm nights (TN90P) and warm days (TX90P) increased, although of smaller magnitudes and at lower levels of significance. Both absolute temperature indices: TNn (annual minimum value of daily minimum temperature) and TXx (annual maximum value of daily maximum temperature) in Table 1 exhibit a similar pattern with large negative changes. The absolute magnitude of the gradients of two curves is higher than standard error, even though none of them are statistically significant at the $5 \%$ level. TX and TN, on average, decreased by nearly $1^{\circ} \mathrm{C}\left(0.42^{\circ} \mathrm{C} / 10\right.$ year $)$ and $1.5^{\circ} \mathrm{C}\left(0.61{ }^{\circ} \mathrm{C} / 10\right.$ year $)$ between 1986 and 2011 . The extreme 
temperature range (ETR) index calculated from the difference between TXx and TNn indicates a statistically weak upward trend (Fig. 3(c)), which interprets that minimum temperature cooled at a faster rate than the maximum temperature. Consequently, the annual count of days when TX $>$ $45^{\circ} \mathrm{C}$ (98th percentile) decreased by 5 days from 8 to 3. Similarly, the annual count of days when $\mathrm{TN}<15^{\circ} \mathrm{C}$ (2nd percentile) increased by 10 days from 5 to 15 .

\section{Precipitation indices, 1977-2011}

We found a relatively significant increase in most of the precipitation indices except for consecutive dry days (CDD) and consecutive wet days (CWD). Some indices are less important in arid regions like Oman given the fact that on average it rains on only around 7 days per year. Consequently, CWD has a small variation that in Muscat, ranges between 1 and 4 days only. Figure 4(a) shows that there has been relatively significant increase in annual maximum 1-day precipitation (RX1day). Similarly, annual maximum consecutive 5-day precipitation (RX5day) index indicates a stronger positive trend, which is significant at $10 \%$ level (Table 2). The contribution from very wet days to the annual precipitation total shows a steady increase (Fig. 4(b)), even though its trend is significant at $75 \%$ only (Table 2 ). The positive trend in simple daily intensity index is also clear and

(a)

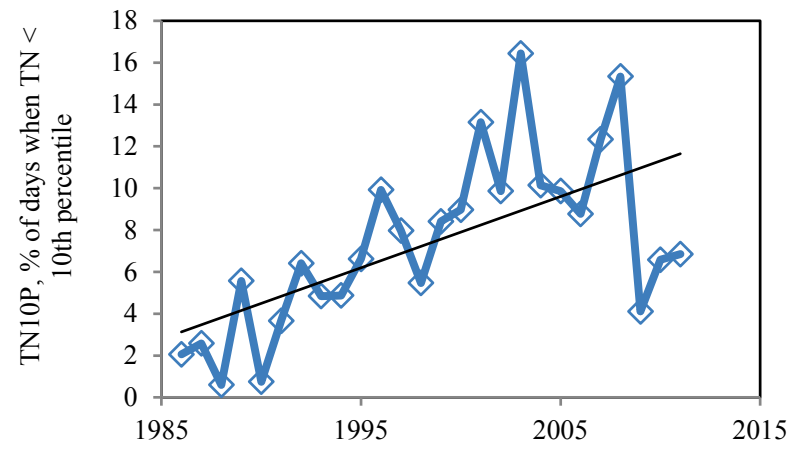

(b)

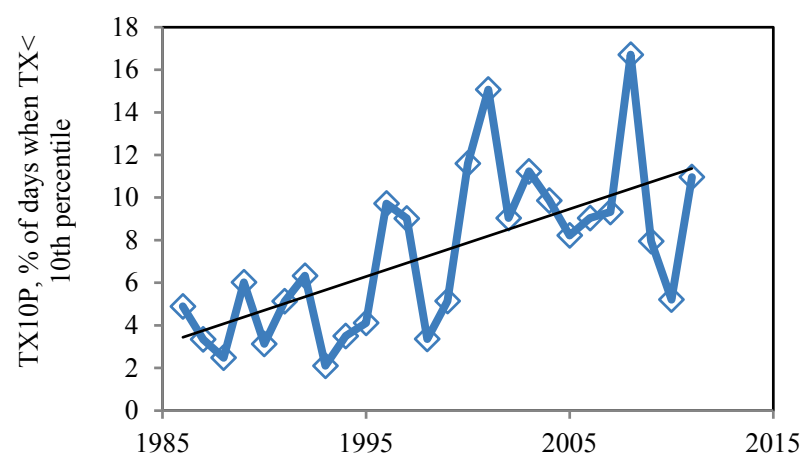

(c)

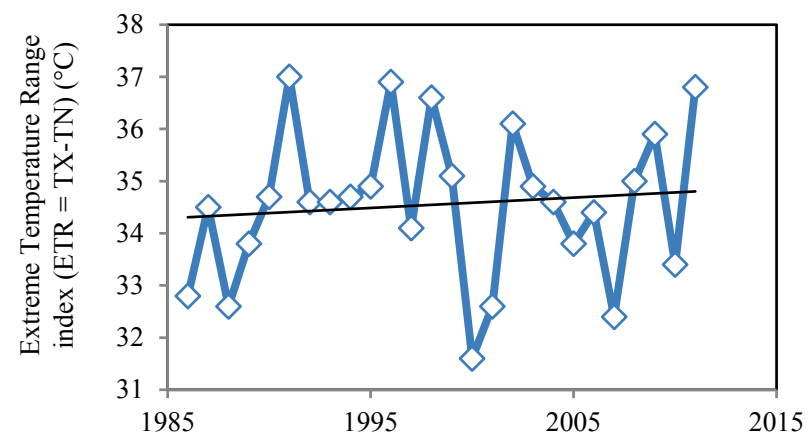

Fig. 3 Trends of different temperature indices relative to the base period 1986-2000: (a) cold nights, (b) cold days (c) Extreme Temperature Range Index. 
Table 1 Test statistics of temperature indices.

\begin{tabular}{llllll}
\hline Index & Slope & Standard error & P-value & \multicolumn{2}{c}{ Significant at } \\
& & & & $5 \%$ & $10 \%$ \\
\hline TN10P & 0.341 & 0.085 & 0.001 & Yes & Yes \\
TN90P & 0.079 & 0.068 & 0.256 & No & No \\
TX10P & 0.317 & 0.079 & 0.001 & Yes & Yes \\
TX90P & 0.192 & 0.07 & 0.012 & Yes & Yes \\
TXx & -0.042 & 0.032 & 0.209 & No & No \\
TNn & -0.061 & 0.031 & 0.061 & No & Yes \\
ETR & 0.020 & 0.038 & 0.611 & No & No \\
\hline
\end{tabular}

(a)

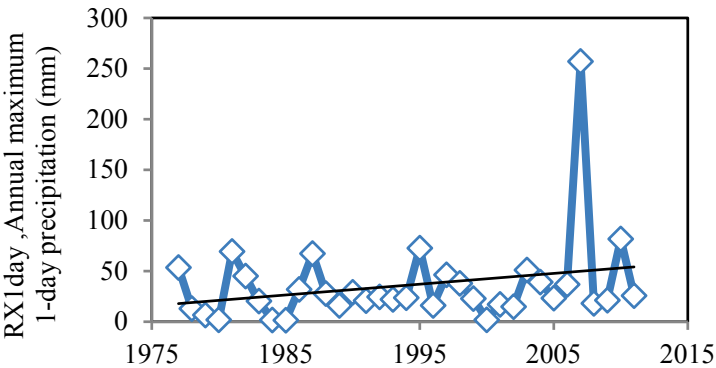

(b)

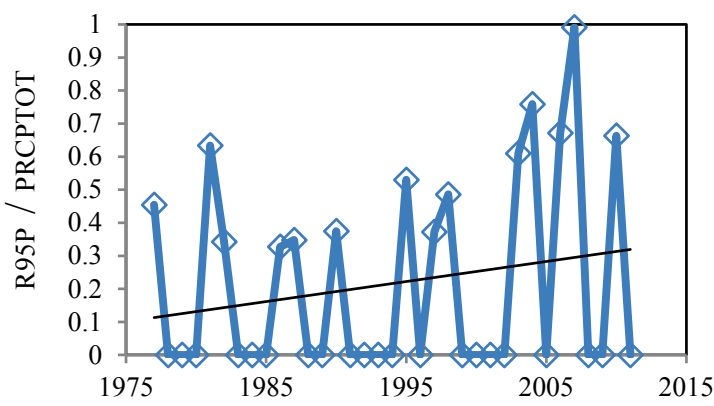

(c)

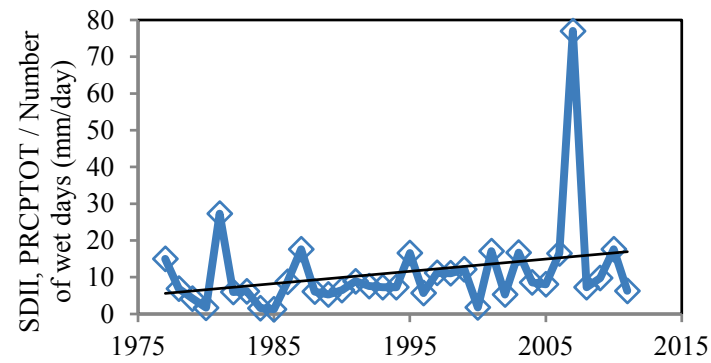

Fig. 4 Trends of different precipitation indices: (a) heavy precipitation, (b) contribution from very wet days, and (c) daily intensity.

reasonably significant. Results of all these indices lead us to conclude that enhanced extreme precipitation events have strongly contributed to increase total precipitation in Muscat, which rises at an average rate of $6 \mathrm{~mm}$ per decade between 1977 and 2011.

\section{Probability distribution changes}

In order to understand the changes in extreme precipitation and temperatures over different periods of time, we examined temporal changes in the TNn, TXx and RX1day indices over two consecutive time periods. Table 3 shows the estimated parameters of the GEV distribution and their significance. Inspection of standard errors shown in parentheses reveals that the values for the 
shape parameter are larger than the standard deviation from zero for TNn for both time periods. In particular, the probability distribution function (PDF) for the recent time period shows a significant decrease in TNn. On the other hand, change of the TXx is less obvious between two time periods. In particular the value of 1999-2011 shape parameter is less than the standard error. This indicates that a two parameters distribution (a Gumbel distribution) fits the data. Figure 5

Table 2 test statistics of precipitation indices.

\begin{tabular}{llllll}
\hline Index & Slope & Standard error & P-value & \multicolumn{2}{l}{ Significant at } \\
& & & & $5 \%$ & $10 \%$ \\
\hline CDD & 0.326 & 1.999 & 0.872 & No & No \\
CWD & 0.001 & 0.017 & 0.949 & No & No \\
RX1day & 1.146 & 0.742 & $\mathbf{0 . 1 3 2} *$ & No & No \\
RX5day & 1.299 & 0.755 & $\mathbf{0 . 0 9 5 *}$ & No & Yes \\
R95P & 1.059 & 0.973 & 0.284 & No & No \\
R95P/ PRCTOT & 0.006 & 0.005 & $\mathbf{0 . 2 2 4} *$ & No & No \\
SDII & 0.335 & 0.209 & $\mathbf{0 . 1 1 9 *}$ & No & No \\
\hline
\end{tabular}

*Significance level $>25 \%$.

Table 3 Estimated parameters of the Generalized Extreme Value (GEV) distribution.

\begin{tabular}{|c|c|c|c|c|c|c|}
\hline Index & $\begin{array}{l}\text { Time } \\
\text { period }\end{array}$ & $\begin{array}{l}\text { Parameters o } \\
\text { location }(\mu)\end{array}$ & $\begin{array}{l}\text { he GEV dist } \\
\text { scale }(\sigma)\end{array}$ & $\begin{array}{l}\text { ution } \\
\text { shape }(\xi)\end{array}$ & $\begin{array}{l}\text { K-S test } \\
\text { significant at } \\
5 \% \text { level }\end{array}$ & $\begin{array}{l}\text { Reject Gumbel } \\
\text { Hypothesis }\end{array}$ \\
\hline \multirow[t]{2}{*}{ TNn } & 1986-1998 & $12.5(0.59)$ & $1.76(0.66)$ & $-0.82(0.46)$ & Yes & Yes \\
\hline & 1999-2011 & $12.3(0.00)$ & $1.00(0.00)$ & $-1.01(0.00)$ & Yes & Yes \\
\hline \multirow[t]{2}{*}{ TXx } & 1986-1998 & $47.0(0.12)$ & $0.37(0.11)$ & $0.45(0.31)$ & Yes & Yes \\
\hline & 1999-2011 & $46.0(0.56)$ & $1.37(0.52)$ & $-0.26(0.59)$ & Yes & No \\
\hline \multirow[t]{2}{*}{ RX1day } & 1977-1994 & $16.6(4.2)$ & $14.9(3.2)$ & $0.07(0.24)$ & Yes & No \\
\hline & $1995-2011$ & $23.1(4.9)$ & $18.3(4.3)$ & $0.38(0.19)$ & Yes & Yes \\
\hline
\end{tabular}

Standard errors are shown in parentheses

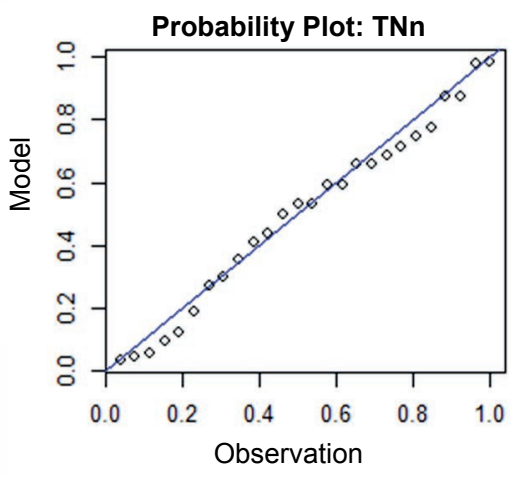

Return level Plot: TNn

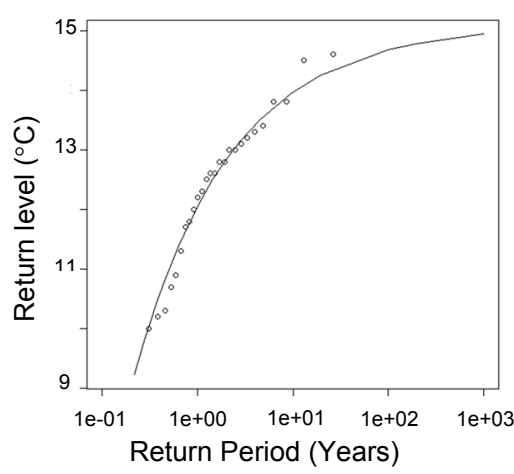

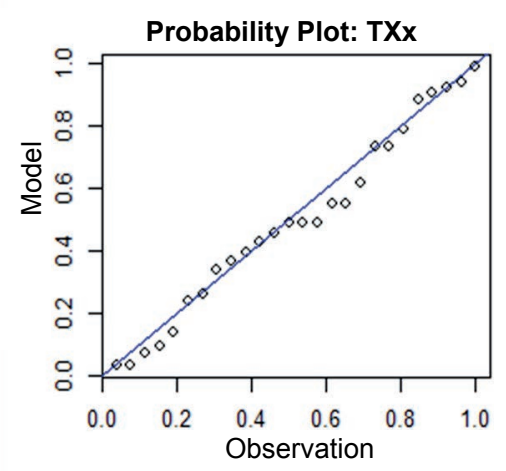

Return level Plot: TXx

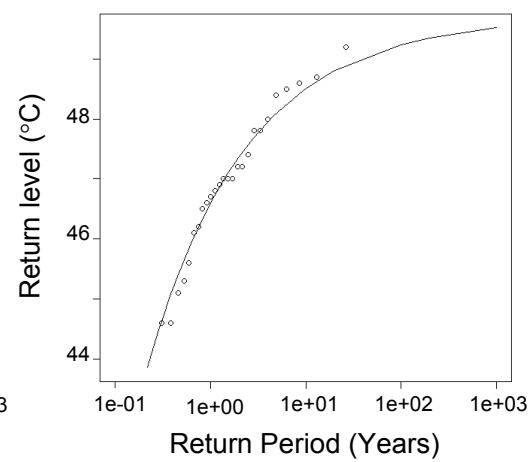

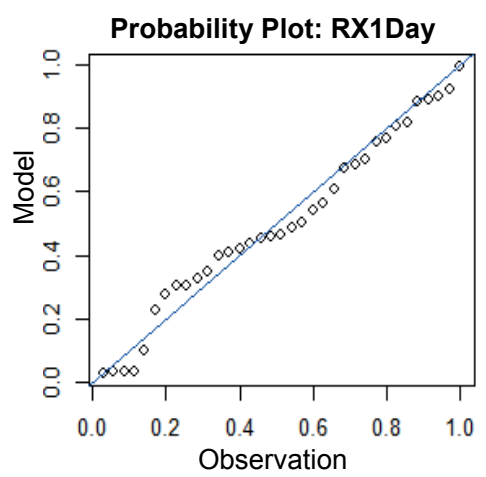

Return level Plot: RX1day

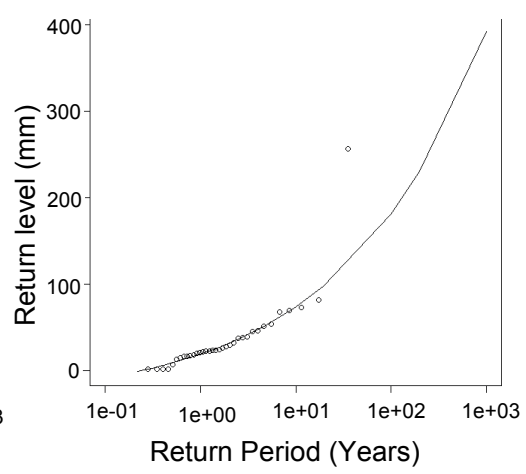

Fig. 5 Diagnostic and return level plots for TNn, TXx and RXlday indices. 
presents the diagnostic plots and return level plots for TNn, TXx and RX1day indices obtained considering the whole data sets. Similar plots were generated for data split into two time periods. Probability plots show good agreement between observations and model probabilities. The plots of return level allow us to estimate the expected return level for each return period. In particular, we examined changes in return level between two time periods. Accordingly, the estimated return level of TNn for a 10 -year return period is $13.2^{\circ} \mathrm{C}$ over $1999-2011$, which is approximately $1^{\circ} \mathrm{C}$ less than the return level of 1986-1998. Similarly, the return level of TXx for the 10-years return period has also decreased in the recent time period but the difference between 1986-1998 and 1999-2011 time periods are less obvious (only $0.3^{\circ} \mathrm{C}$ ).

For the RX1day index, there is a clear sign of change between two time periods. The less significant shape parameter for the period of 1977-1994 (Table 3) indicates that RX1day trend during this time period is towards less extreme. In contrast, a significantly higher shape parameter for the period of 1995-2011 represents a clear sign of increase in annual maximum 1-day precipitation. Consequently, the estimated return level of RX1day for a 10-year return period is 95 $\mathrm{mm}$ in 1995-2011, which is about 70\% higher than the return level for the period 1977-1994.

\section{CONCLUSIONS}

In this study, precipitation and temperature extremes in Muscat, Oman were evaluated using a set of climate indices. Temporal change of climate extremes were analysed in terms of 10 -years return values of annual extremes for two time periods, and the following conclusions were obtained.

- Between 1986 and 2011, temperature extremes showed significant increases in the occurrence of cold days and cold nights, while the occurrence of warm nights and warm days showed smaller increases at lower levels of significance. The minimum temperature decreased by nearly $1.5^{\circ} \mathrm{C}$ at a rate of $0.61^{\circ} \mathrm{C} / 10$ year between 1986 and 2011 . The 10 -year return values of annual minimum temperature during 1999-2011 and 1986-1998 were very different, with the former being colder by approximately $1{ }^{\circ} \mathrm{C}$ than the latter, on average. The maximum temperature extremes are cooling, where minimum temperature decrease at a faster rate than the maximum temperature, with changes being pronounced in recent decades.

- The annual total precipitation index shows a tendency toward wetter conditions with a 6 $\mathrm{mm} / 10$ year trend between 1977 and 2011. There is also a significant tendency for stronger precipitation extremes according to many indices. The contribution from very wet days to the annual precipitation totals steadily increases with significance at $75 \%$ level. Inspection of PDF in two time periods revealed that extreme precipitation occurred with greater magnitudes in recent decades. For example, the return level of RX1 day for a 10-years return period in 19952011 is approximately $70 \%$ higher than the return level for the period of 1977-1994. These results indicate that the long-term wetting signal apparent in total precipitation can be attributed largely to the increases in extreme precipitation in recent decade.

\section{REFERENCES}

Alexander, L. V., et al. (2006) Global observed changes in daily climate extremes of temperature and precipitation. Journal of Geophysical Research 111, D05109, doi:10.1029/2005JD006290.

Al-Rawas, G. A. \& Valeo, C. (2010) Relation between Wadi drainage characteristics and peak flood flows in arid northern Oman. Hydrological Sciences Journal 55(3), 377-393.

Beniston, M., et al. (2007) Future extreme events in European climate: an exploration of regional climate model projections.Climatic Change 81, 71-95.

Easterling, D. R., et al. (2000) Observed climate variability and change of relevance to the biosphere. Journal of Geophysical Research 105, 101-114.

Fowler, H. J., et al. (2005) New estimates of future changes in extreme rainfall across the UK using regional climate model integrations, 1. Assessment of control climate. Journal of Hydrology 300, 212-233.

Groisman, P. Y., et al. (2005) Trends in intense precipitation in the climate record. Journal of Climate 18, $1326-1350$.

Jenkinson, A. F. (1955): The frequency distribution of the annual maximum (or minimum) values of meteorological elements. Quarterly Journal of the Royal Meteorological Society 81, 158-171.

Kharin, V. V. and Zwiers, F.W. (2005) Estimating extremes in transient climate change simulations. Journal of Climate 18, $1156-1173$.

Rafy, M. E. \& Hafez, Y. (2008) Anomalies in meteorological fields over northern Asia and its impact on Hurricane Gonu. 28th Conference on Hurricanes and Tropical Meteorology, 1-12. 